\title{
E-participation For Increased Citizen Engagement? A Case From Uganda
}

\section{*Martin Nilsson, **Sirkku Männikkö Barbutiu}

${ }^{*}$ Dept of Computer and Systems Sciences, Stockholm University, PO Box 7003, SE-16407 Kista, Sweden, emj.nilsson@gmail.com;

**Dept of Computer and Systems Sciences, Stockholm University, PO Box 7003, SE-16407 Kista, Sweden, sirkku@dsv.se

Abstract: Implementation of an e-participation system in a low-income region with poor infrastructure, limited access to ICT and low awareness of civic rights and responsibilities, is challenging and requires thorough understanding of the contextual conditions and requirements. The present study provides a qualitative analysis of the implementation phase of an e-participation platform, mapping the specific factors that play key roles in defining access to and use of the system by citizens. The social and political context, as well as the design and management of the platform, are found to be the two crucial dimensions in defining its successful use.

Keywords: e-participation, enablement, engagement, digital platform, Uganda

\section{Introduction}

Continuously evolving collaborative digital technologies pave the way for interesting societal experimentation in the area of e-democracy/e-participation. Techno-optimism has often characterised many of these projects even though results may have turned out to be meagre in terms of increased citizen participation in governmental decision making. Another central notion that can be observed in these projects is their geographical concentration to Western, high-income, industrialised countries (Cullen, 2009; Alonso, 2009; Conroy \& Evans-Cowley, 2006).

In this paper, we will examine a rare case of an e-participation project situated in the African continent. Our study analyses the Ugandan "MML" (Me and My Leader) initiative, to shed light on the specific conditions that prevail in the implementation and use of deliberative digital systems in low-income countries, where issues of inadequate infrastructure, varying levels of digital literacy and various traditions of decision-making challenge development projects with e-democracy/e-participation aspirations.

The notions of e-democracy and e-participation, are often applied interchangeably. In this paper, we have chosen to use 'e-participation' with the meaning that the purpose is to involve citizens in the decision-making process and engage them in a political dialogue. E-participation may include 
providing information to citizens, having online discussions where citizens can participate, carrying out polls and facilitating dialogue between citizens and authorities (Spirakis, Spiraki \& Nikolopoulos, 2010). The primary goal of e-participation may be seen to be the engagement of citizens in the governance process through the wider access facilitated by technology (Au-Shanab \& Al-Dalou', 2016). Sæbø et al. (2008) see e-participation as the extension and transformation of participation in societal democratic and consultative processes and they assign ICT, primarily the Internet, a mediating role in this process.

In the literature on e-democracy/participation, we can find several issues related to the democratic potential of the technologies developed. One central concern is the poor quality of the citizendecision maker dialogue that the digital consultation platforms can provide: instead of quality they tend to provide quantity. (Farina, Epstein, Heidt \& Newhart, 2013; Moss \& Coleman, 2013; Shulman, 2009).

On the other hand, low participation levels in deliberative dialogues undermine the legitimacy of the decisions based on such deliberations (Benkler, Roberts, Faris, Solow-Niederman \& Etling, 2015; Herz, Kaplan \& Cardozo, 2016). For example, an e-participation project in Denmark (Hansen and Reinau, 2006) shows that even if the number of Internet users is high in the region, the e-participation system was mainly used by middle-aged, well-educated men. In contrary to the vision of an open debate by the project initiators, it was mainly one small segment of the population who got engaged in the system and discussed topics. This study shows that even if citizens are enabled to use an e-participation system, only a small segment of the population may be interested in getting engaged in a citizen dialogue through the system.

For these reasons, it is important to deepen our knowledge on how to increase both the quality and quantity of e-participation, through building structures that combine the old and new ways of citizen participation and thus eventually strengthen democratic practices in societies.

The research questions of this study are:

1) How can citizens be enabled to use an e-participation system in a region with limited access to ICT?

2) What factors influence citizens' engagement in governance issues when implementing an eparticipation system?

\section{Methodology}

Empirical data for this qualitative study has been collected through intensive field work with participant observation and semi-structured interviews of key informants. The principal author of this article spent almost two months within the non-governmental organization Toro Development Network (ToroDev) in Fort Portal, Western Uganda and participated in the implementation phase of the e-participation system as an active team member. Participant observation has helped the researchers to understand the context, and design the semi-structured interviews. During the field study period at ToroDev, the researcher participated in meetings, worked on the design of the 
platform's website and joined field visits. Throughout the project, detailed field notes were taken and a research diary was kept for documentation.

ToroDev staff were vital for contacting citizens, journalists and leaders. The leaders that participated in the study worked for the local government in Kabarole district. ToroDev staff, journalists and leaders were interviewed individually. Focus group interviews with citizens were carried out in four villages. Interpreters were used when the interviewees had a limited command of the English language. In total, four citizen groups, four ToroDev employees, three journalists and three leaders were interviewed.

Detailed information about the design ideas of the e-participation system "MML" was collected from the project team as well as their thoughts about enablement and engagement. In addition, journalists who had been active in similar projects in the region were contacted to learn about their experiences in the field.

The study has followed the research ethical guidelines and informed consent was obtained from all participants in the study.

\section{Framing the Study - Central Concepts}

\subsection{E-participation}

E-participation is generally defined as ICT-supported participation in processes involved in government and governance. Processes may concern administration, service delivery, decisionmaking and policy-making, enabling communication and deliberation amongst citizens and with their political authorities (Bwalya, K. J. \& Zulu, S. F. , 2012).

The term 'e-government' started to emerge in the mid-1990s; the concept of 'e-participation' emerged in the early 2000s. Initially, e-participation and 'e-democracy' were seen as equivalent, but today the terms have somewhat different meanings. In the US, the term 'digital government' was initially used instead of e-government. In some literature, e-government has been used as a synonym for e-participation and in some, as a more abstract term that covers both e-government and e-participation. (Peristeras et al., 2009)

To diverse e-participation and e-government, Peristeras et al. (2009) differentiated the two interface systems: society-to-administrative and society-to-political, within the governance system. The society-to-administrative interface focuses on public service delivery and internal and external communication between government, business and citizens. To facilitate the society-to-administrative interaction, e-government systems are being used. The second interface mentioned by Peristeras et al. (2009) - society-to-political - relates to the interaction between citizens and government during analysis, formulation and selection of public policies. To facilitate the society-to-political interaction, e-participation systems are being used.

When trying to define e-participation in relation to e-democracy, there are some different opinions. Some still argue that the concepts are synonymous, while some argue that e-participation is 
broader than e-democracy, since it may also relate to non-political engagement, e.g. patient participation (Alarabiat, Soares \& Estevez, 2016). However, by some, e-democracy is seen as an overall super term that involves e-voting, e-activism, e-participation etc. (Milakovich, 2010; Mahrer \& Krimmer, 2005)

\subsection{Defining enablement and access to ICT}

Macintosh (2004, p. 3) wrote:

"E-enabling is about supporting those who would not typically access the Internet and take advantage of the large amount of information available."

In order to enable someone who has no access to the Internet, one needs to understand the meaning of the word 'access' in this context.

The notion of digital divide is closely related to issues of access. Initially, the term referred to the physical access to computers and the Internet, meaning that if a (family) household had a connected computer, all family members had access to the Internet. However, the meaning of access has shifted and some researchers have argued that one cannot only focus on the physical access to ICT. (van Dijk \& van Deursen, 2010)

Van Dijk (2012) has developed the model Four Successive Kinds of Access in the Appropriation of Digital Technology. In this model, the term access is defined as a process with four different stages. First of all, van Dijk argues that the user needs to be motivated to start using new technology, then the user needs to have material access and the digital skills to use the digital medium. According to Van Dijk (2012), once the user has reached the stages of "motivational access", "material access" and "skills access", the user can reach the final stage "usage access".

Another factor that affects usage is gender. In sub-Saharan Africa, there is in general a gap between men and women in terms of access to ICT. Factors such as income, education and social position prevent women from having the same level of access as men. Even if women - compared to men - spend more money on ICT in relation to their salary, in general they spend less in total, since men tend to have higher salaries than women. Across the African continent, the percentage of educated men is higher than the percentage of educated women. Since low education level is related to digital skills, the digital skills of women are affected negatively. Harassment in public spaces, such as Internet cafés, and heavy work load, also limit women from using ICT. In some African cultures, ICT is considered a "men's thing". (Gilwald, Milek \& Stork, 2010)

\subsection{Defining engagement - digital and non-digital}

Macintosh (2004, p. 3) wrote:

"E-engaging with citizens is concerned with consulting a wider audience to enable deeper contributions and support deliberative debate on policy issues".

'Engagement' in her "Level of e-participation" model (see figure 1), refers to engagement as a topdown consultation, where public authorities ask for consultation on specific topics. 
Smith and Dalakiouridou (2009) argue that engagement in a context of policy making is,together with involvement and empowerment, a near synonym to participation. Further, the authors defined participation as formal and informal inputs on decision- and policy-making within the political and government sphere.

According to Olphert and Damodaran (2007), citizens may choose not to get engaged in topics where they feel that they have not much to contribute, or if they feel that their input will not be considered. They argued that it is important to overcome these reservations in order to increase public engagement. They noticed that when citizens can see that their input is considered, the willingness to engage increases.

Researchers disagree on what possible effects increased Internet use might have on the civic and political engagement of citizens. Some argue, that since the Internet is mainly used for entertainment, citizens have less time to devote to social and civic activities; instead of, for example, joining civic groups, people choose to entertain themselves on the Internet. Other scholars maintain that increased Internet usage has a positive impact on civic and political engagement, since the Internet offers users an effective, time-saving way to get engaged in political questions. It has also been argued that the Internet may encourage a broader set of citizens to get politically active. For example, in an analysis of 38 studies about the Internet's effect on political engagement, it was found that increased Internet usage did not decrease citizens' political engagement. However, the study did not find a correlation between increased Internet usage and substantial increased political engagement. (Boulianne, 2009)

For the theoretical point of departure, we found the model of A. Macintosh (2004) useful. The model describes three levels of e-participation (see figure 1). The 'enabling' level consists of the aspects of accessibility and understandability. Accessibility involves reaching out to a wider audience with diverse technical and communicative skills. Understandability is about providing information that will be understandable for the receivers.

The second level in Macintosh's model is about 'engaging'. Engaging includes consulting a wider audience in deliberative debate. Macintosh defines engagement in this context as a form of top-down consultation. (Macintosh, 2004).

Macintosh's third level, 'empowering' is characterised by a bottom-up approach. Instead of reacting to government led initiatives, citizens become producers of policies and are given the opportunity to set the political agenda and to be involved in policy formulations. (Macintosh, 2004)

This fine-grained model, differentiating between levels of participation, helps us analyse and understand the conditions and processes of citizen participation in a structured manner. Since the model addresses both accessibility and engagement, the key elements in our research questions, the model is applied as a conceptual frame for the current study. The applicability of the Macintosh model is further investigated in the particular context of Uganda, with the aim of contributing to the development of the model through new empirical insights. 
Figure 1: Levels of participation. Macintosh (2004)

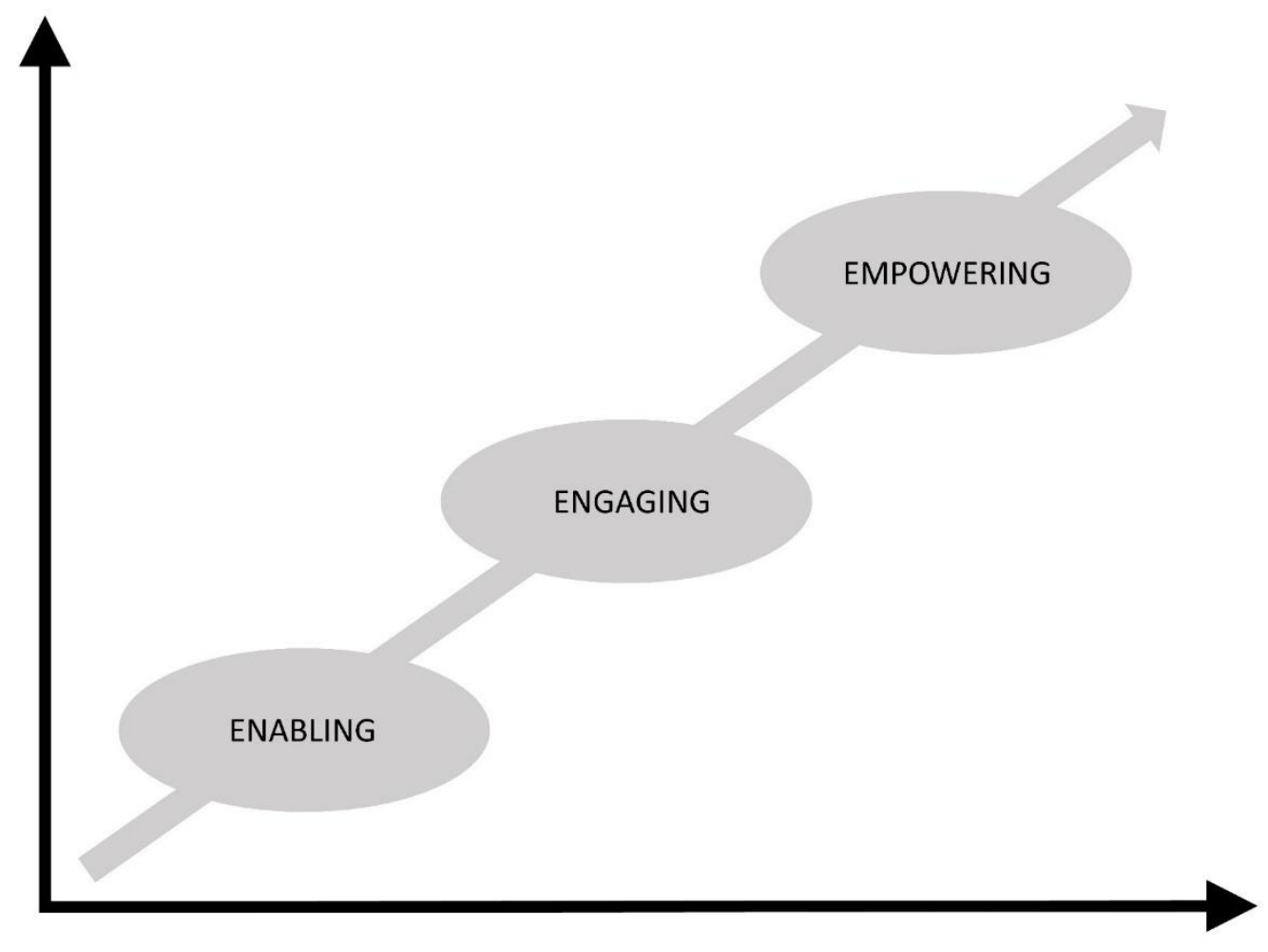

\section{Context of the Study}

In this section, a contextual description of the specific Ugandan e-participation project is given.

\subsection{ICT and e-participation in Uganda}

According to UNICEF (2017), 22\% of the population of Uganda use the Internet and there are 55 mobile phones for every 100 citizens. Since it is common in Africa for people to own multiple phones (Aker \& Mbiti, 2010), it would probably be an over-estimation to consider this meaning that 55\% of the population have access to a mobile phone. However, it is also common that mobile phones are shared by several individuals (Aker \& Mbiti, 2010), which would indicate that the number of mobile phone users may be higher than 55\% of the population. Stam (2014) argued that when analysing national access to ICT statistics, one should have in mind that in sub-Saharan Africa, there is usually a wide variance within countries, where the number of citizens having access to ICT is greater in urban areas compared to rural areas.

In the Ugandan ICT policy (2014), ICT is identified as a key enabler in the economic and social sectors. In the policy, the term e-participation is not used. However, some chapters refer to the concept; local governments are for example encouraged to:

"Deploy and use ICTs in improving citizens' participation in national planning and civic matters" (Ugandan Ministry of Information and Communication Technology, 2014 p. 50). 
Regarding enablement, local governments are encouraged to:

"Attract local initiatives aimed at promoting investments in Community Radio stations, Internet, computerization, ICT literacy training, etc." (Ugandan Ministry of Information and Communication Technology, 2014, p. 51).

The policy urges increased public-private partnerships and the private sector is encouraged to actively participate in policy formulations. In the policy, there is a chapter that refers to e-government where it is stated that an open data platform, which gives citizens access to government information, will be implemented. (Ugandan Ministry of Information and Communication Technology, 2014)

Regarding access, the Ugandan ICT policy states that extending the ICT backbone to cover the entire country is to be prioritised. The policy aims to increase the number of phones to 90 for every 100 citizens (it was 50 for every 100 citizens when the policy was written). The broadband speed is to be increased and the cost of broadband is intended to be decreased from $180 \%$ of per capita income to $10 \%$ of per capita income. (Ugandan Ministry of Information and Communication Technology, 2014). The policy acknowledges the high rate of ICT illiteracy within the country and the existing digital divide between urban and rural areas, as well as between men and women. In order to improve the ICT skills of the population, the policy suggests that ICT will be part of the curriculum at all levels of education. It is also stated that within schools, opportunities and assistance will be provided for the disadvantaged, people with special needs, women and for young people to acquire ICT skills. (Ugandan Ministry of Information and Communication Technology, 2014)

In a quantitative study carried out in Uganda (Wakabi \& Grönlund, 2015), the results showed that citizens strongly believed in ICT's ability to make it easier to engage with leaders and other citizens in order to increase social accountability. The study also shows that social media and Facebook in particular, were the participants' favourite medium through which to express their opinions. Participants showed less interest in engaging in online discussions or calling into TV or radio shows. Most respondents were hesitant in expressing anti-government opinions, in particular about the current president Yoweri Museveni. Other impediments that affected the respondents' level of engagement were limited accessibility, affordability and illiteracy.

In 2011, prior to the general elections in Uganda, the NGO National Democratic Institute launched the platform UgandaWatch. By using the platform, citizens could report electoral irregularities by sending SMS messages. Hellström (2015) found that UgandaWatch had some limitations. Poor people, for example, were not able to participate, since the SMS messages were not toll-free. It was also discovered that as the reported irregularities from the public were only published on a website, the information was missed by many reporters, as they didn't visit the website. By only publishing the results online, users without access to the web did not see the effect of their reporting. An important reason why citizens chose to use UgandaWatch was that they didn't know of any other way to report electoral irregularities. This indicated that the platform filled a gap in the electoral process, and even if it had some limitations, it shed light on irregularities that might not have surfaced without it. (Hellström, 2015) 


\section{2. "MML" (Me and My Leader)}

Supported by the research findings (Baguma, Karema \& Njeri Githinji, 2016) identifying the importance of access to information, and the need for information sharing platforms as ways towards accountability and transparency, the NGO Toro Development Network (ToroDev) initiated an e-participation project called 'MML' (Me and My Leader) in an attempt to address insufficient service delivery in Uganda.

ToroDev was established in 2005. The non-governmental organisation has offices in Kampala and Fort Portal in Uganda. ToroDev's main focus area is ICT4D. The NGO has several years of experience in running projects within the field. The vision of ToroDev is

"A society empowered with knowledge and leadership skills for positive livelihoods." (ToroDev, n.d., "WhoWe Are@ ToroDev" section).

The organisation is primarily active in the health, education and economic development sectors. In 2016, ToroDev carried out a baseline study to evaluate the requirements of an e-participation system in Uganda and Kenya. (ToroDev, n.d.) This baseline study found that radio was the technology that most participants had access to, followed by television, smartphone, computer and mobile phones without internet. Participants' average Internet expenditure was 17500 Ugandan shillings (around \$5) / month. Based on these results, ToroDev recommended the implementation of a crossdomain platform where citizens could use multiple ICT devices. Researchers also stressed the importance of having a toll-free number that could be used by citizens. (Gamukama \& Nalumaga, 2017)

In 2017, the 'MML' website (mmlonline.org) was published. The website has three sections: eInformation, e-Discussion and e-Decision Making. In the e-Information section, information that may be of interest to citizens is posted, for example, government budgets and health information. The e-Discussion section gathers inputs from citizens. ToroDev posts questions and citizens are expected to respond with their ideas and answers. Discussions may, for example, cover what can be done to prevent child marriage or how forests can be protected. In the e-Decision Making section, reports based on citizens' input will be published. Citizens can also send SMS messages to toll-free numbers and report their opinions.

In late 2017, the MML platform was being promoted by ToroDev. A radio jingle was played on the local radio in western Uganda and posters with instructions about how to use the system were distributed. ToroDev arranged training of trainers sessions, where citizens were instructed about how to use the platform; these citizens then trained others in their area.Results

The field work resulted in rich and detailed data which has been subject to careful thematic analysis. The transcribed interviews were coded. Codes that had common signification and were related to the research questions were grouped into categories. Codes that were not related to the research questions were discarded. The categories were finally linked to the two main themes 'enablement' and 'engagement' which were derived from the research questions. The category 'gender' contained codes that provided information that was related to both enablement and engagement, hence the category was linked to both of the themes. See all the themes and categories in Table 1. 
Table 1: Themes and categories

\begin{tabular}{|l|l|}
\hline \multirow{5}{*}{ Themes } & Categories \\
\hline \multirow{5}{*}{ Enablement } & Affordability of different ICT tools \\
\cline { 2 - 2 } & Gender \\
\cline { 2 - 2 } & Language \\
\cline { 2 - 2 } & Location \\
\cline { 2 - 2 } & Promotion \\
\cline { 2 - 2 } & Skills \\
\hline \multirow{5}{*}{ Engagement } & Awareness \\
\cline { 2 - 2 } & Budget limitations \\
\cline { 2 - 2 } & Fear \\
\cline { 2 - 2 } & Feedback \\
\cline { 2 - 2 } & Gender \\
\cline { 2 - 2 } & Relevance of topics \\
\cline { 2 - 2 } & System management \\
\hline
\end{tabular}

\subsection{Enablement}

The data collected shows that several factors affect how citizens can be enabled to access ICT and eparticipation platforms.

\subsubsection{Affordability of different ICT tools}

Different ICT tools are related to different costs. The financial status of the participants affected which ICT tool they chose to use and their ability to access an e-participation system. One of the leaders explained that most people could not access the Internet due to the cost of airtime. He thought that radio broadcasts were a more effective way to reach citizens. Another leader pointed out that issues of affordibility of the Internet is not limited to citizens. It is also something that the government is struggling with:

"Sometimes we do not have the Internet, we write proposals to NGOs and ask if they can sponsor our Internet".

Since people have limited access to the Internet, the implementation of an e-participation system cannot rely on just using the Internet in the current context. 
The MML platform allows users to use radio, SMS and the Internet as communication tools. Radio is free of charge and for SMS, a toll-free number is available. However, both radios and mobile phones consume power. One citizen pointed out how this sometimes can be a problem

"These radios use batteries, but sometimes the radios are not in use since people cannot afford to buy batteries. It cost 2000 shilling for one week of radio usage".

Even if it is cheaper to use radio than the Internet, it still costs money to use the radio.

Operators in the region offer both a full Internet bundle and a limited bundle, called social bundle. The social bundle only allows users to access social media such as Facebook, Twitter, WhatsApp and Instagram, while the full Internet bundle allows users to access all sites on the Internet. One employee of ToroDev said:

"People with Internet bundle will be able to access the platform and people using social bundle will not be able to access ongoing questions posted on the platform, so they will fail to get out their view".

This means that citizens who use a social bundle need to be considered when planning for an eparticipation platform since they will not be able to access a "non-social media" website such as MML.

One community leader pointed out that even if there are costs related to using an e-participation system, it would still be more favourable for the community:

"Community meetings are costly because we have to mobilize for them, putting announcements on the radio and transport people. MML will help us, because, it is somehow cheaper, and even the poor can access it because it just a matter of sending an SMS".

A consequence of implementing an e-participation system may be that the costs of participating in governance issues are being transferred from the community to individuals. The community may not need to pay for organising meetings, but citizens will need to pay for using ICT.

\subsubsection{Gender}

Various participants talked about how gender affects access to ICT. Some women said that in households where the radio is being shared by the whole family, it is the man who makes the decisions about usage. An interviewee said that she sometimes couldn't listen to programmes that were of interest to her, such as programmes about farming and gardening because her husband wanted to listen to football programmes. Even if women have a radio in their household, they may not have complete access to it since it is the man who decides how it is used.

In the region, women are normally expected to spend more time on domestic work than men. This results in men having more time to get engaged in, for example, e-participation. One journalist said:

"Men will have all the time they need. When the ladies are cooking, the man can listen to radio and put a comment. When ladies are doing other housework, the man can use the Internet". 
One employee of ToroDev said that they previously have had participatory radio shows at $8 \mathrm{pm}$. During the shows, the number of women who participated was low. ToroDev finally learned that during this time, a lot of women were busy doing domestic work, which hindered them from accessing the radio shows in terms of calling in or sending SMS messages. The unequal domestic workload excludes women from e-participation.

The majority of the interviewees explained that a woman and a man usually have separate phones. However, it seems that the man's phone is for the man only but the woman's phone is sometimes used by the man as well. One participant said:

"The man's power may be low, he will then ask the woman about using her phone, but the woman can never access the man's phone".

This example illustrates that the issue of technology ownership is a complex one, and reflects practices related to gender, often unknown to outsiders.

\subsubsection{Location}

In Uganda, some of the rural areas have limited infrastructure which affects access to ICT negatively. One journalist said:

"In most villages in Uganda, they have no power, in terms of electricity, their phones may run out of battery, and they don't have any place to buy data ... and the Internet connections haven't reached all villages".

Power failures prevented citizens from calling into participatory radio shows since the listeners' phones were out of battery. The journalist proposed that discussion topics should be posted ahead of the radio shows to let citizens send in their input throughout the day. If the time span when citizens can participate is extended, the chance that citizens will have a working phone during the time span increases.

Citizens living in rural areas experienced difficulties in accessing the Internet. When discussing if smartphones and Internet could be used to access an e-participation system, one citizen living in a rural village said:

"Few people have smartphones, and few people can go to the cafes to deal with the Internet".

Another citizen explained that it is expensive to go to the more urban areas where the Internet cafes are located. When discussing the usage of mobile phones without internet, citizens were more enthusiastic due to the greater dissemination. One citizen said:

"I'm hopeful since we will use these ordinary phones and even our grandmothers and grandfathers and the youth will participate since they have these ordinary phones and SMS is free".

If targeting citizens living in rural areas, an e-participation platform needs to be accessible through well-established ICT tools, such as radio or SMS. 


\subsubsection{Language}

Even if English is the official language of Uganda, not all citizens can speak the language. Currently, the website of MML is in English, although previous radio shows that ToroDev broadcast were in the local language. Most participants agreed that in order to reach as many citizens as possible, it was essential to have topics in the local language. One journalist pointed out that English could only be used in an e-participation system if it is the urban elite that is being targeted. If targeting people like farmers, the journalist argued that local languages should be used. Other citizens said that it is only the ones that went to school that understand English. In order to enable citizens with different educational backgrounds to use an e-participation system, it is suggested that the platform should be available in local languages.

It was emphasized that the wording in the discussion needs to be of such a nature that people with different educational backgrounds and of different ages can understand it. One citizen said:

"We need to come down and break down this discussion so that even my grandmother or my mother or somebody looking after their cows or goats can understand".

By using a simple language, more people may understand the discussions.

An employee of ToroDev suggested that families can help each other to interpret from English to a local language:

"If someone is not educated, they can use a grandson or granddaughter to interpret. At least 3/10 are educated and they can help others who want to use the system".

Some citizens can be helped by others to understand the language of the e-participation platform. However, it makes the citizens who don't speak English dependent on others.

\subsubsection{Promotion}

Promotion is vital for the successful implementation of an e-participation system. If citizens did not know about the 'Me and My Leader' system or if they did not know how to use it, they wouldn't have access to the system. Promotion through radio and social events was proposed as an adequate promotion method in the region. One journalist suggested that the e-participation platform should be promoted through radio jingles. Several actors pointed out social events as an opportunity to promote the system, and one citizen said:

"Go to the churches, mosques, social events or any place where people are gathering. When it is a wedding or a funeral here, it is a community business. There will be 300-500 people, a big number of people, you could have a presentation and even demonstrate the system at these events".

The result shows that it is essential to consider the local context when planning for the promotion of an e-participation system. Using radio and visiting social events may not be a successful promotion method in other parts of the world.

Having local connections that can support promotion campaigns was suggested as being valuable. During recent years, ToroDev has built a network of civic groups in the villages, which work 
closely with ToroDev and were involved in the specification phase of the platform. ToroDev involved civic groups in the promotion campaign and let them be local messengers and trainers following up, for example, the radio jingles. A ToroDev staff member said that citizens who hear the radio jingles can go to civic group members and ask for an explanation of e-participation and the MML platform. By having local promoters, trust can be built in locations where the implementers are not present.

Civic group members were positive about supporting the promotion of MML; however, they also emphasized the need to be supported by ToroDev. On civic group member said:

"Sometimes we need facilitation for transport etc. Once I did this work in the field and I had to walk because I had no money".

Even if it lies in the interest of the civic group members to promote e-participation, they may still need funding.

\subsubsection{Skills}

If a citizen doesn't know how to use an ICT device, he or she does not have real access to that device and will not be able to access an e-participation system through it. A ToroDev employee argued that ICT skills are a crucial factor when discussing access:

"Access speaks about the availability of equipment, ordinary phones, smartphones, tablets, laptops etc. But access is also about skills".

To have real access to ICT, you also need to have the skills to use it.

For e-participation, citizens do not have access if they don't know how to participate. To give citizens real access to MML, training of trainers was suggested as a method of transferring knowledge within communities. One civic group member said:

"The first thing is to take some few people and give them more knowledge about the system, then after that, those people have got that knowledge, they have to come back to their people - the grassroots and also teach them".

Another citizen emphasised that it is important to show citizens how to use the system practically. Citizens prefer knowledge transfers through physical meetings within communities.

Since leaders have an important role in e-participation, they also need to gain skills about the platform in use. A ToroDev employee also said:

"The promotion will also include training of leaders so that they can also really feel comfortable using the system".

If leaders don't know how to use an e-participation system, they don't have real access to the system and will not be able to use it. 


\subsection{Engagement}

Even if citizens are enabled to use an e-participation platform, there are still factors that influence citizens' decisions on engaging or not. In this chapter, factors that affect citizens' engagement in eparticipation are presented.

\subsubsection{Fear}

Freedom of expression without the fear of reprisals is still a condition not realized in many countries. This became evident in the context of the MML project. A journalist noted that citizens had avoided participating in radio discussions, since they were afraid of being isolated and being seen as someone who was challenging the leaders. In the MML platform, the last digits of the phone number are hidden when citizens send their comments through SMS. When using the web interface, people can choose to post their comments anonymously. One employee of ToroDev said:

"People don't want to give out their name due to their self-security. They think that if they comment something, anything may happen to their family".

The results indicate that the possibility of commenting on issues anonymously may affect engagement positively.

\subsubsection{Budget limitations}

Some citizens expressed despair over the fact that they had already reported problems in the service delivery, but were told that the leaders couldn't solve their problem due financial constraints. One citizen said:

"The government is aware, but they tell us that they are not allowed to recruit more staff in primary schools".

A leader at district level said that the government has limited resources and that they feel overwhelmed by demand, and can't always deliver. The government's incapability to implement solutions due to budget limitations may discourage citizens to get engaged, as they cannot see the results of their engagement.

\subsubsection{Feedback}

Several participants argued that in order to keep citizens active, it is of high importance that leaders give feedback on the citizens' input. One employee of ToroDev talked about their previous experience in the field and how lack of feedback resulted in decreased participation:

"We previously had radio discussions where citizens allowed to call in and express themselves but the feedback from leaders was slow and citizens engagement dropped".

Citizens confirmed that their engagement would probably decline if they didn't get any feedback on their input. Citizens were aware of the leaders' situation and that even if they participate in MML, leaders may not always be able to solve their problems. However, citizens highlighted the 
importance of feedback even when leaders were not able to solve a problem. One citizen said that it would be enough to get feedback quarterly or every six months. To promote citizens' engagement, leaders need to meet citizens expectations for feedback.

Leaders agreed on the importance of giving feedback. One leader said:

"I would feel that that the step where we give feedback is the most important".

Leaders also highlighted the fact that their budget is limited and that they would not be able to implement all the citizens' demands. The leaders argued for the importance of informing the citizens about what they can and cannot do. One leader said that they would prefer to get summarised reports of citizens' inputs and then give feedback on the reports. To live up to citizens expectation on feedback, leaders' concerns need to be addressed as well.

\subsubsection{Gender}

As already discussed, gender may affect access to an e-participation system. However, gender may also affect engagement. A journalist with experience in broadcasting radio shows where citizens call in and discuss government matters, argued that due to the culture in Uganda, women do not get engaged to the same degree as men. A citizen said that men are more likely to get engaged in an eparticipation system, based on the fact that the local culture has made men more dominant than women, the citizen said:

"Basically, the culture here made men to be in front".

If not actively promoting women's engagement in the region, it is likely that more men than women will use an e-participation system.

\subsubsection{Awareness}

Some participants argued that citizens' lack of awareness of their rights in society kept them from getting engaged. One citizen reasoned that some citizens are not aware of their role in the society; instead of demanding their rights and the service they are entitled to, they stay quiet. A journalist argued that, in some regions, it is not a common practice to make demands of the government. Instead, people accept the current situation. The journalist said:

"When they go to their health centers that have stock-outs or no diagnosing equipment, they just go home, don't say anything, it is as usual".

If people are not aware of how their situation can be improved, there are no incentives to use an e-participation system.

One of the leaders interviewed, discussed the fact that some elected leaders are not well educated about how to behave as a leader and that they don't know how to express themselves; the leader said:

"They are not contributing. Why? Because they are not educated and they don't know what to do". 
If leaders are not well aware of their role, they may not know how to express themselves in an eparticipation system.

\subsubsection{System management}

Leaders and citizens argued that some regulation of the system would be needed. One leader thought that abusive language should be filtered out. The leader said that if a leader was abused, the leader wouldn't respond to that comment. Another leader said that it would be essential that citizens' comments were summarised in reports. The leader said that if he/she had to go through all the comments, he/she would never use the system. The leader argued:

"If I got 100 comments a day, I would never visit that site, I can't. But a summarized report, could be monthly, it would be better".

In order to keep an e-participation system trustworthy and to keep peoples' interest in the system, one citizen argued that comments about nonsense should be filtered out. The citizen argued that since the system is free of charge, there might be quite a lot of irrelevant comments; the citizen said:

"The information needs to be authentic and genuine, because some people may lose interest if the system is just sending nonsense".

The level of participation,among leaders and citizens, in some degree depends on how the system is managed.

\subsubsection{Relevance of topics}

Citizens expressed that they would like to use MML to report problems in the service delivery. One citizen argued about some of the problems that would be appropriate to discuss in an e-participation system:

"For example, here at the health center, we have a problem with the maternity ward, the one we have is small but we are receiving many mothers who come to deliver from around here, we also have problems that the health workers arrive late at work, and leaving early. And in the education, we have problems with poor performance, some schools are lacking some structures, like toilets, staff houses, and other are lacking teachers".

To get citizens engaged, topics that are of interest in the specific region should be addressed.

\section{Discussion}

In this study, the e-participation system MML was examined to understand how citizens could be enabled to use such a system and what factors affect citizens engagement in an e-participation system. 


\subsection{Discussion on results}

The study was carried out in the Kabarole district in western Uganda. The leaders that were interviewed worked at district level. The citizens who participated in the study lived in four different villages in Kabarole district. The staff of ToroDev and the journalists interviewed were based in Fort Portal, the capital of the Kabarole district.

To answer RQ1 "How can citizens be enabled to use an e-participation system in a region with limited access to ICT?" several aspects need to be considered. This study confirms Gilwald et al.'s (2010) finding that heavy work load prevents women from accessing ICT. The long-term solution for this problem may be to introduce changes in the role of women. To support women at present, however, e-participation radio shows should be adjusted to women's daily schedules in a better way. To enable the less educated part of the population to access an e-participation system, the result shows that it is essential to use the local language in the system. Van Dijk's (2012) model Four Successive Kinds of Access in the Appropriation of Digital Technology points out that digital skills are one of the essential elements when talking about access. Our results suggest that citizens can learn how to use the system through training of trainers sessions. Well-focused promotion is also crucial. Several participants concluded that promotion in social gatherings, for example in conjunction with church and mosque visits, is preferable in the region. Previous studies (ITU, 2015; UNICEF, 2017; Gamukama \& Nalumaga, 2017) have highlighted which tools citizens use to access the Internet, without further examination of the access levels. Our study shows that "social bundles" which only give a limited access to the Internet and exclude everything else but social media platforms, are widely used by those with meagre funds. When planning for a future e-participation system, it is essential to keep in mind that some people who say that they have access to the Internet, may only have access to social media. To enable these users to access an e-participation platform, the platform needs to be available through social media or other ICT tools that are available for this user segment. The result of the study also shows that since people may not have access to ICT 24/7 (due to e.g. power outbreaks or no Internet access), it is preferable to use ICT platforms that enable users to access the system at any time, e.g. SMS and web-based platforms (in addition to radio shows).

For RQ2 “What factors influence citizens” engagement in governance issues when implementing an e-participation system?", the results show that multiple factors affect citizens engagement. Leaders feedback to citizens is essential when running an e-participation platform, since it affects the engagement of citizens. This confirms Olphert and Damodaran's (2007) finding that citizens' willingness to engage is increased when they feel that their input is recognized. Knoop (1995) found that there is a correlation between work involvement and commitment, to ensure leaders' commitment to the platform and ensure that they act on citizens' input. We suggest that leaders should be involved in the early stages of a project. Another important finding is the realisation about how weak citizens' awareness of their own civil rights and their role in the society is. An e-participation system may serve as an important channel for citizen education. In line with Gilwald et al. (2010), our study confirms that the social position of women in Uganda prevents them from getting engaged in governance issues as they are not expected to take part in such engagements. As to leaders and their engagement, it is important that the system supports their work rather than increases their workload, which is why summarising reports were suggested as a solution. It was also found that abusive 
language may discourage leaders from using the system. Another important aspect in the use of the system is anonymity, which must be guaranteed for all users in order to provide a safe and trusting environment. Our findings confirm those of Wakabi and Grönlund (2015) about Ugandan citizens' fear of expressing anti-government opinions.

\subsection{Revisiting Macintosh's model}

In Macintosh's model (Macintosh, 2004), the three levels of enabling, engaging and empowering are positioned on a rising linear graph. The model is meant to describe the level of participation in an edemocracy initiative. In the model, the $X$ and $Y$ axis have not been defined. Our study found that a number of factors influence enablement and engagement. Some of the factors depend on the social and political context, such as affordability, language, skills, location, gender inequality, fear, budget limitations and awareness. The context affects the level of participation. For example, without any technical skills, a citizen cannot be enabled to use an e-participation system. If citizens are afraid to get engaged or are not aware of their rights, it is not likely that the e-participation system will reach the engaging level in Macintosh's model.

For citizens who possess technical skills and are eager to participate, an e-participation platform needs to be designed and managed in a way that allows and encourages users to become enabled, engaged and empowered. We found that in the design and management of an e-participation system, the social and political context needs to be taken into consideration. For example, when implementing an e-participation system in a location where people have limited access to the Internet, it is advisable to allow other forms of communication such as radio and SMS. To reach the levels of enabling and engaging, this study found there are a number of pertinent factors connected to the design and management of an e-participation system, that should be considered. The findings of this study show that the possibility of reaching different levels in Macintosh's model depends on how well the factors of promotion, relevance of topics, system management and feedback are taken into consideration, given the social and political context. As this study indicates that the level of eparticipation depends on the "Social and political context" as well as the "Design and management of platform", we suggest that these dimensions could be added to the model defining $\mathrm{X}$ and $\mathrm{Y}$ axis (see figure 2). 
Figure 2: Macintosh's model of level of participation with defined $X$ and $Y$ axis

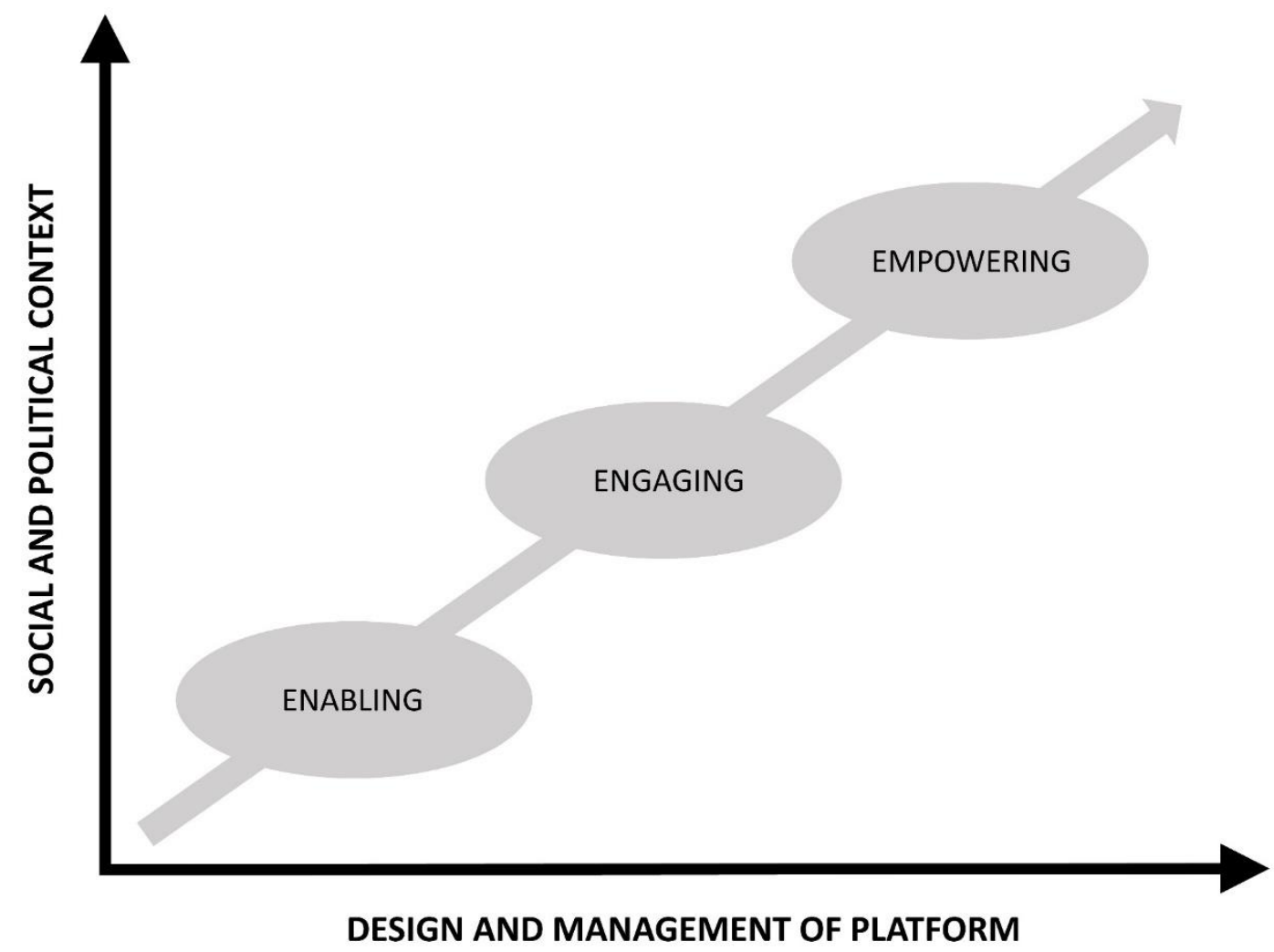

\subsection{Ethical and societal consequences}

The use of a technical solution in the context of citizen engagement is always related to ethical and societal issues requiring careful consideration. The result show, for example, how leaders would prefer to receive summarised reports of the users' inputs. This places great responsibility on those who are to compile the reports. What should be included and what can be ignored in the reports? There is a risk for misleading filtering where some citizens' input could be ignored. The possibility of anonymous submission may lead to misuse, where if some actors post their opinion multiple times, it may give the leaders an misleading view. For citizens, before getting engaged in an eparticipation system, it is important to know who is responsible for the system and how the information is intended to be used. The intentions of the implementers should preferably be presented during promotion campaigns and be available on the platform's website.

\subsection{Future work}

This study has focused on how citizens can access an e-participation system and what factors affect their engagement within a specific socio-cultural and economic context of a country in the Global South. In addition, the specific socio-technical system MML with its specific functionalities frame this study. This frame may be regarded as a limitation of the study as well as its strongpoint as the study provides a detailed analysis and identification of some key challenges related to eparticipation. 
For further work, we would like to investigate more closely the role of local leaders. Our results revealed that even leaders have limited access to ICT and that there are factors that affect their participation. One important finding of our study is how leaders' feedback plays a crucial role in citizens' engagement with the system and civic affairs. If leaders don't get engaged in an e-participation system and don't listen to citizens' input, the project is doomed to fail. A focused study on leaders' access and incentives to use an e-participation system would be valuable for future implementations. Inclusion of leaders at different political levels in such a study would provide a more holistic understanding of the leader perspective.

The use of social bundles would also need further investigation, to build a better picture of the conditions of Internet access guiding decisions on future implementations of e-participation systems.

\section{References}

Hansen, H., \& Reinau, K. (2006). The Citizens in E-participation. Electronic Government, 70-82. Retrieved from https://link-springer-com.ezp.sub.su.se/chapter/10.1007\%2F11823100_7

Aker, C. J., \& Mbiti, M. I. (2010). Mobile Phones and Economic Development in Africa. Journal of Economic Perspectives, 24(3), 207-232. Retrieved from https://pubs.aeaweb.org/doi/pdfplus/10.1257/jep.24.3.207

Alarabiat, A., Soares, D., \& Estevez, E. (2016). Electronic Participation with a Special Reference to Social Media - A Literature Review. International Conference on Electronic Participation (pp. 41-52). Guimarães: Springer. Retrieved from https://link.springer.com/chapter/10.1007/978-3-319-45074-2_4

Al-Dalou', R., \& Abu-Shanab, E. (2013). E-PARTICIPATION LEVELS AND TECHNOLOGIES. The 6th International Conference on Information Technology, (pp. 8-10). Retrieved from https://www.researchgate.net/profile/Emad_Abu-Shanab/publication/273632293_E-participation_levels_and_technologies/links/552d38fb0cf29b22c9c4c7b3.pdf

Alonso, Á. I. (2009). E-PARTICIPATION AND LOCAL GOVERNANCE: A CASE STUDY. Theoretical and Empirical Researches in Urban Management, Vol. 4, No. 3 (12), 49-62. Retrieved from http://www.jstor.org/stable/pdf/24872436.pdf

Baguma, J., Karemera, C., \& Githinji, F. N. (2016). Advancing ICT4Governance in Eastern Africa: The Case of Me \& My Leader (MML) e-participation System Design. 2016 Conference for E-democracy and Open Government, (pp. 35-44). Retrieved from http://ieeexplore.ieee.org.ezp.sub.su.se/stamp/stamp.jsp?tp=\&arnumber $=7781907$

Boulianne, S. (2009). Does Internet Use Affect Engagement? A Meta-Analysis of Research. Political Communication, 26(2), 193-211. Retrieved from http://www.tandfonline.com/doi/pdf/10.1080/10584600902854363?needAccess=true

Bwalya, K. J., \& Zulu, S. F. (2012). Handbook of Research on E-Government in Emerging Economies: Adoption, E-Participation, and Legal Frameworks (2 Volumes) (pp. 1-1020). Hershey, PA: IGI Global. doi:10.4018/978-1-4666-0324-0 
Conroy, M., \& Evans-Cowley, J. (2006). E-participation in planning: an analysis of cities adopting on-line citizen participation tools. Environment and Planning C: Government and Policy 2006, 371-384. Retrieved from http://journals.sagepub.com.ezp.sub.su.se/doi/pdf/10.1068/c1k

Cullen, L. S. (2009). Participation 2.0: A Case Study of e-participation within the New Zealand Government. 2009 42nd Hawaii International Conference on System Sciences, 1-10.

Gamukama, E., \& Nalumaga, R. (2017). Baseline \& Needs Assessment Report - On e-participation for Good Governance Processes to Improve Public Services Delivery in Uganda and Kenya. Kampala.

Gilwald, A., Milek, A., \& Stork, C. (2010). Gender assessment of ICT access and usage in Africa. Towards Evidence-based ICT Policy and Regulation., 1. Retrieved from http://citeseerx.ist.psu.edu/viewdoc/download?doi=10.1.1.1001.9667\&rep=rep1\&type=pdf

Hellström, J. (2015). Crowdsourcing as a tool for political participation? - the case of Ugandawatch. International Journal of Public Information Systems, 11(1), 1-19. Retrieved from http://www.ijpis.net/ojs/index.php/IJPIS/article/view/131/pdf

ITU. (2015). Measuring the Information Society Report. Geneva, Switzerland. Retrieved 02 05, 2018, from https://www.itu.int/en/ITU-D/Statistics/Documents/publications/misr2015/MISR2015-w5.pdf

Knoop, R. (1995). Relationships Among Job Involvement, Job Satisfaction, and Organizational Commitment for Nurses. The Journal of Psychology, 643-649. Retrieved from https://www-tandfonlinecom.ezp.sub.su.se/doi/pdf/10.1080/00223980.1995.9914935?needAccess=true

Macintosh, A. (2004). Characterizing E-participation in Policy-Making. Proceedings of the 37th Hawaii International Conference on System Sciences - 2004.

Mahrer, H., \& Krimmer, R. (2005). Towards the enhancement of e-democracy: identifying the notion of the 'middleman paradox'. Information systems journal, 15(1), 27-42. Retrieved from http:/ / onlinelibrary.wiley.com.ezp.sub.su.se/doi/10.1111/j.1365-2575.2005.00184.x/full

Milakovich, M. E. (2010). The Internet and Increased Citizen Participation in Government. eJournal of eDemocracy and Open Government, 1-9. Retrieved from file:// C:/Users/mani01/Downloads/22214-1-PB.pdf

Olphert, W., \& Damodaran, L. (2007). Citizen participation and engagement in the design of e-government services: The missing link in effective ICT design and delivery. Journal of the Association for Information Systems, 8(9), 491-507. Retrieved from http:/ / web.a.ebscohost.com.ezp.sub.su.se/ehost/pdfviewer/pdfviewer?vid=1\&sid=9324e2ce-8051-4ae3-98918c45408180fa\%40sessionmgr4007

Peristeras, V., Mentzas, G., Tarabanis, K., \& Abecker, A. (2009). Transforming E-government and E-participation through IT. IEEE INTELLIGENT SYSTEMS, 14-19. Retrieved from http://ieeexplore.ieee.org.ezp.sub.su.se/stamp/stamp.jsp?tp=\&arnumber $=5286168$

Sæbø, Ø., Rose, J., \& Skiftenes Flak, L. (2008). The shape of eParticipation: Characterizing an emerging research area. Government Information Quarterly, 400-428. Retrieved from https:/ / ac-els-cdncom.ezp.sub.su.se/S0740624X0700055X/1-s2.0-S0740624X0700055X-main.pdf 
Smith, S., \& Dalakiouridou, E. (2009). Contextualising Public (e)Participation in the Governance of the European Union. European Journal of ePractice, 7(11), 47-50. Retrieved from https:/ /www.researchgate.net/profile/Simon_Smith6/publication/216701352_Contextualising_Public_eParticipation_in_the_Governance_of_the_European_Union/links/02e7e51efcca03f934000000.pdf

Spirakis, G., Spiraki, C., \& Nikolopoulos, K. (2010). The impact of electronic government on democracy: edemocracy through e-participation. Electronic Government, An International Journal, 7, 75-88. Retrieved from https://www-inderscienceonline-com.ezp.sub.su.se/doi/abs/10.1504/EG.2010.029892

Swedish Research Council. (2017). Good Research Practice. Retrieved from https:/ / publikationer.vr.se/en/product/good-research-practice/

ToroDev. (n.d.). ToroDev. Retrieved 03 19, 2018, from http://torodev.co.ug

Ugandan Ministry of Information and Communication Technology. $(2014,10)$. NATIONAL INFORMATION AND COMMUNICATIONS TECHNOLOGY POLICY FOR UGANDA. Uganda. Retrieved from https://ict.go.ug/wp-content/uploads/2018/11/ICT_Policy_2014.pdfUnicef. (2017). The State of the World's Children 2017 Statistical Tables. Retrieved 04 09, 2017, from https:// data.unicef.org/resources/state-worlds-children-2017-statistical-tables/

van Dijk, J. (2012). The Evolution of the Digital Divide The Digital Divide turns to Inequality of Skills and Usage. Digital Enlightenment Yearbook, 57-75. Retrieved from http://ebooks.iospress.nl/publication/31966

van Dijk, J., \& van Deursen, A. (2010). Internet skills and the digital divide. New Media \& Society, 13(6), 893911. Retrieved from http://journals.sagepub.com/doi/abs/10.1177/1461444810386774

van Stam, G. (2014). Framing 'ICT Access in Rural Africa'. 11th Prato CIRN Conference, (pp. 13-15). Retrieved from http://www.academia.edu/download/34916356/Framing_ICT_Access_in_Rural_Africa_CIRN_2014.pdf

Wakabi, W., \& Grönlund, Å. (2015). Citizen-to-Citizen vs. Citizen-to-Government eParticipation in Uganda: Implications for Research and Practice. E. Tambouris et al. (Eds.): ePart 2015. 9249, pp. 95-107. Springer, Cham. Retrieved from https:/ /link-springer-com.ezp.sub.su.se/chapter/10.1007/978-3-319-22500-

5_8\#citeas

\section{About the Authors}

\section{Martin Nilsson}

Martin Nilsson studied ICT For Development at Stockholm University and holds a master's degree in Computer and Systems Science. He has experience from working in ICT projects related to education, farming, accessibility and e-participation in sub-Saharan Africa. Since 2014, Martin is a board member in Swedish Cacine association which works for development through education in Guinea Bissau. Martin is currently working as a project manager in the private sector.

\section{Sirkku Männikkö Barbutiu}

Sirkku Männikkö Barbutiu holds a PhD in Human-Machine-Interaction. She is Associate Professor in Information Society at the Department of Computer and Systems Sciences, Stockholm University, Sweden. She is director of doctoral studies and coordinates the ICT4D research group. She is board member of SPARC (Swe- 
dish Participatory Action Research Consortium). Her research interests include ICT for development, technology enhanced learning, social media, ICT in teacher education, digital humanities, digital media ethics, and action research. Currently, she is involved in research on female entrepreneurship in developing regions, and ICT support for disabled women in Europe. 